\title{
Sensor Ketinggian Air menggunakan Multimode Fiber Coupler
}

\author{
Samian* dan Supadi \\ Departemen Fisika,Fakultas Sains dan Teknologi, \\ Universitas Airlangga Surabaya \\ Kampus C Unair Jl. Mulyorejo, Surabaya 60115
}

\begin{abstract}
Intisari
Deteksi ketinggian air secara kontinyu telah berhasil dilakukan berbasis pada sensor pergeseran menggunakan multimode fiber coupler dengan membran dari bahan polyisoprene sebagai reflektor. Prinsip kerja sensor menggunakan perubahan tekanan hidrostatis akibat perubahan ketinggian air dalam tangki untuk menggeser membran yang diberi bahan reflektor. Pergeseran membran menyebabkan perubahan daya optis berkas balik cahaya pantulan dari membran yang masuk ke kanal sensing fiber coupler. Perubahan daya optis berkas balik terkopel ke kanal deteksi fiber coupler dan terbaca dalam bentuk tegangan keluaran detektor optis. Resolusi ketinggian air yang mempu dideteksi sebesar $1 \mathrm{~mm}$ dengan rentang ketinggian $45 \mathrm{~mm}-320 \mathrm{~mm}$. Daerah linier dan sensitivias sensor yang dihasilkan masing-masing sebesar 10,4 $\mu \mathrm{V} / \mathrm{mm}$ dan $130 \mathrm{~mm}-320 \mathrm{~mm}$.
\end{abstract}

KATA KUNCI: multimode fiber coupler, sensor ketinggian air

\section{PENDAHULUAN}

Aplikasi serat optik sebagai sensor telah mengalami perkembangan yang sangat pesat akhir-akhir ini. Hal tersebut dikarenakan penggunaan serat optik sebagai sensor memiliki keunggulan antara lain tidak kontak langsung dengan obyek pengukuran, tidak menggunakan listrik sebagai isyarat, akurasi pengukuran yang tinggi, kebal terhadap induksi listrik maupun magnet, serta masih banyak keunggulan-keunggulan lainnya. Dengan berbagai macam teknik dan desainnya, serat optik telah dikembangkan sebagai sensor pergeseran [1], suhu [2] , vibrasi [3] , tekanan [4], ketinggian zat cair dan parameter lainnya.

Sensor ketinggian zat cair dapat dikontruksi berdasarkan prinsip hidrostatis, kapasitif, ultrasonik, gelombang mikro, inframerah, elektro-mekanik, radiometri dan optik. Prinsip kerja sensor ketinggian zat cair tersebut dapat bersifat kontak langsung (intrusive) maupun tidak langsung (non-intrusive) dengan zat cair. Berdasarkan prinsip optik, telah berhasil diteliti sensor ketinggian zat cair menggunakan serat optik dengan probe berupa prisma [5] maupun elemen sensitif berbentuk kerucut [6] . Prinsip kerjanya adalah perubahan daya optis cahaya pantulan total di dalam probe akibat perubahan indeks bias medium di sekitar probe. Teknik yang lebih sederhana berhasil dilakukan dengan mendeteksi rugi daya optis cahaya dalam serat optik yang dipoles dan dilengkungkan sebagai sensor yang kontak secara langsung dengan zat cair [7] . Teknik ini tidak dapat mendeteksi ketinggian zat cair secara kontinu, tetapi pada titik-titik tertentu yang menandakan ketinggian zat cair. Deteksi ketinggian zat cair melalui pergeseran panjang gelombang Bragg yang dihasilkan

*E-MAIL: samian_fsteunair.ac.id dari Fiber Bragg Grating (FBG) telah berhasil dilakukan [8] . Pergeseran Panjang gelombang Bragg terjadi karena perubahan panjang FBG akibat terdorong atau tertarik oleh pelampung yang berada pada zat cair. Teknik lain yang berhasil dikembangkan adalah menggunakan dua buah serat optik sebagai pemancar dan penerima berkas cahaya melalui sebuah cermin (head sensor) sebagai colimator. Amplitudo berkas cahaya pantulan dari permukaan zat cair yang diterima serat optik penerima melalui cermin dapat mengindikasikan ketinggian zat cair [9]. Teknik opto-fluidic dengan electronically controlled variable fokus lens atau ECVFL berhasil dikembangkan [10]. Deteksi dilakukan merekam profil spasial intensitas berkas cahaya berdaya rendah pantulan dari permukaan cairan sebagai fokus lensa (ECVFL). Ketinggian cairan ditentukan dengan cara membandingkan ukuran spot berkas dengan panjang fokus lensa pada tabel ECVFL.

Berdasarkan sensor pergeseran berbasis modulasi intensitas menggunakan fiber couplerr yang telah berhasil dikembangkan, pada penelitian ini dikontruksi sensor ketinggian zat cair menggunakan prinsip hidrostatis. Tekanan hidrostatis yang bergantung pada ketinggian permukaan zat cair akan dimanfaatkan untuk menekan membran. Pergeseran membran akibat tekanan tersebut dapat dideteksi menggunakan fiber couplerr. Desain sensor tersebut mempunyai keungggulan diantaranya tidak kontak langsung dengan zat cair, mudah intepretasinya serta biaya yang murah.

\section{DESAIN DAN PRINSIP KERJA SENSOR}

Sensor ketinggian zat cair dikontruksi berdasarkan prinsip hidrostatis dan sensor pergeseran berbasis modulasi intensitas menggunakan fiber couplerr. Desain sensor ketinggian zat cair diperlihatkan pada Gambar 1.

Dalam Gambar 1, berkas cahaya masukan dari laser $\left(\mathrm{P}_{i n}\right)$ 


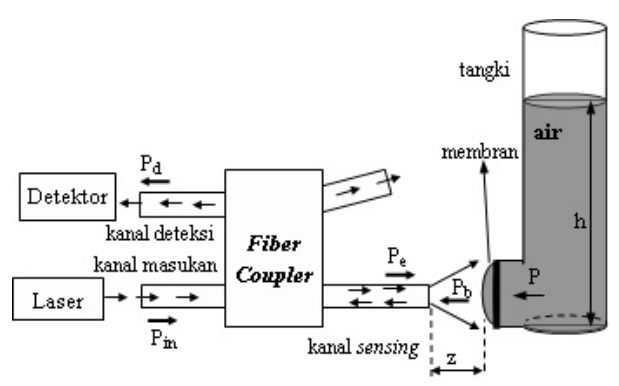

Gambar 1: Desain sensor ketinggian zat cair

sebagian dipancarkan melalui kanal sensing ( $\mathrm{P} e$ ) menuju membran yang dilapisi bahan reflektor pada bagian tengahnya. Berkas cahaya pantulan dari membran sebagian akan masuk kembali ke kanal sensing sebagai berkas balik $\left(\mathrm{P}_{b}\right)$. Berkas balik tersebut kemudian sebagian akan terkopel menuju ke kanal deteksi $\left(\mathrm{P}_{d}\right)$ dan terbaca oleh detektor optis. Besarnya daya optis berkas balik bergantung pada posisi membran terhadap kanal sensing. Dipihak lain, tekanan zat cair pada bagian bawah tangki akan mendorong membran menjadi lebih cembung, sehingga terjadi pergeseran permukaan pantul membran terhadap kanal sensing (z). Pergeseran posisi permukaan membran tersebut akan menyebabkan perubahan daya optis berkas balik. Seperti diketahui bahwa tekanan zat cair bagian bawah tangki dipengaruhi oleh ketinggian zat cair. Dengan demikian ketinggian zat cair dapat dideteksi melalui perubahan daya optis yang terbaca pada detektor optis.

Berdasarkan prinsip hidrostatis, hubungan antara tekanan pada suatu titik (P) dengan ketinggian (h) zat cair ditentukan oleh persamaan berikut :

$$
P=P_{\circ}+\rho_{f} g h
$$

dengan $P_{\circ}, \rho_{f}$, dan $\mathrm{g}$, masing-masing adalah tekanan atmosfir, kerapatan zat cair, dan percepatan gravitasi. Dari Gambar 1, jika diameter pipa tempat membran berada jauh lebih kecil dari ketinggian zat cair, maka dapat diasumsikan bahwa tekanan zat cair pada seluruh bagian membran homogen. Pada penelitian sebelumnya, sensor pergeseran menggunakan multimode fiber couplerr dengan target berupa cermin datar, pergeseran target dalam orde mikrometer mampu dideteksi melalui perubahan daya optis cahaya. Hubungan antara daya optis berkas balik terhadap pergeseran target diperoleh melalui persamaan berikut :

$$
P_{b}=P_{e}\left(1-\exp \left(-\frac{2}{(c z+1)^{2}}\right)\right)
$$

dengan ketentuan $c=\left(2 \tan \left(\sin ^{-1}(N A)\right) / a\right.$. Sedangkan NA dan a masing-masing adalah tingkap numerik dan jari-jari serat optik yang digunakan. Rentang daerah linier antara $\mathrm{P}_{b}$ terhadap z hasil eksperimen diperoleh sebesar $1 \mathrm{~mm}$ [11]

Dalam penelitian ini, hubungan antara ketinggian zat cair (h) dengan daya optis berkas balik ke port sensing $\left(\mathrm{P}_{b}\right)$ belum ditentukan secara analitik. Bahwa ketinggian zat cair

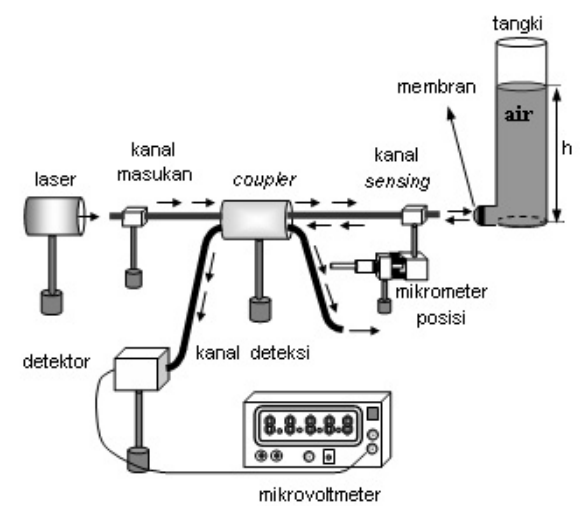

Gambar 2: Susunan peralatan eksperimen sensor ketinggian zat cair menggunakan fiber couplerr.

akan menyebabkan pergeseran permukaan pantul membran sehingga dapat dideteksi melalui perubahan daya optis yang ditangkap detektor optis kiranya dapat dipahami.

\section{EKSPERIMEN}

Susunan peralatan eksperimen diperlihatkan pada Gambar 2. Peralatan yang digunakan terdiri dari laser $\mathrm{He}-\mathrm{Ne}$ (Klasse DIN 58126, 632,8 nm, Uniphase) dengan daya keluaran $1 \mathrm{~mW}$, multimode fiber couplerr, detektor optis OPT 101 (Burr Brown), mikrometer posisi beresolusi $5 \mu \mathrm{m}$ (Uniphase), mikrovoltmeter (Leybold), dan tangki air dari bahan gelas berdiameter $10 \mathrm{~cm}$ dan tinggi $32 \mathrm{~cm}$ yang dilengkapi dengan skala (skala terkecil $1 \mathrm{~mm}$ ). Pada bagian dasar tangki terdapat pipa yang dilengkapi dengan membran dari bahan polyisuprene (tebal 0,07 $\mathrm{mm}$ dan berdiamter $10 \mathrm{~mm}$ ) serta keran yang berfungsi untuk mengeluarkan air dari tangki. Dibagian tengah membran direkatkan reflektor dari bahan aluminium foil berdiamete $5 \mathrm{~mm}$. Multimode fiber couplerr yang digunakan berstruktur $2 \times 2$ dari bahan serat optik plastik berdiameter $1 \mathrm{~mm}$ (diameter core $960 \mathrm{~m}$, tebal cladding $20 \mathrm{~m}$ ) dan panjang $50 \mathrm{~cm}$. Nilai coupling ratio, directivity dan exces loss dari multimode fiber couplerr yang digunakan masing-masing sebesar 0,25, $25 \mathrm{~dB}$, dan 1,37 dB.

Langkah awal eksperimen adalah dengan menempatkan kanal sensing berhimpit, tepat di tengah-tengah (pusat) dan tegak lurus permukaan membran ketika tangki dalam keadaan kosong (permukaan membran dalam keadaan datar). Langkah tersebut dilakukan dengan menggeser kanal sensing menggunakan mikrometer posisi. Setelah kanal sensing digeser mundur menjahui permukaan membran, langkah yang sama dilakukan saat permukaan membran mengalami pergeseran maksimum (menjadi seperti cermin cembung) akibat tekanan air yang memenuhi tangki.

Langkah selanjutnya adalah memasukkan berkas cahaya laser ke kanal masukan fiber couplerr dan mecatat daya optis berkas balik (akibat terpantul oleh permukaan membran) yang sebagian terkopling pada kanal deteksi. Daya optis tersebut terbaca melalui tegangan keluaran detektor optis $\left(\mathrm{V}_{d}\right)$ dan 


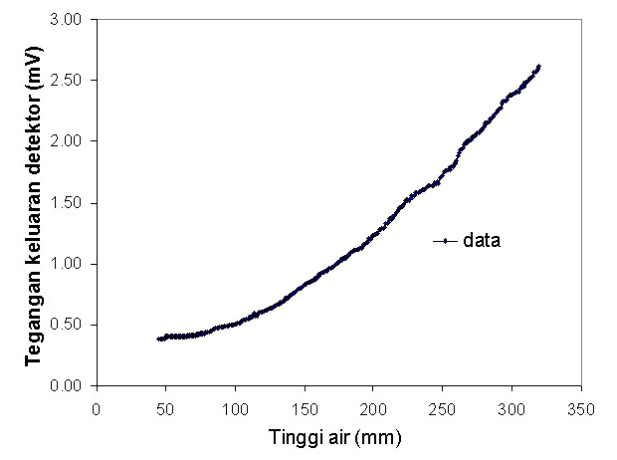

Gambar 3: Grafik data tegangan keluaran sebagai fungsi ketinggian air.

tertera pada mikrovoltmeter. Selanjutnya, tegangan keluaran detektor optis dicatat setiap ketinggian air diturunkan sebesar $1 \mathrm{~mm}$. Ketinggian air dikurangi dengan cara membuka keran tangki secara perlahan. Setelah ketinggian air turun $1 \mathrm{~mm}$, keran ditutup dan tegangan keluaran detektor dicatat. Demikian langkah tersebut dilakukan sampai ketinggian air mencapai $4,5 \mathrm{~cm}$.

\section{HASIL DAN PEMBAHASAN}

Hasil eksperimen berupa data tegangan keluaran detektor sebagai fungsi ketinggian air, diperlihatkan pada Gambar 3.

Dari Gambar 3, terlihat bahwa jangkauan (dinamic range) ketinggian air yang mampu disensor sebesar $45 \mathrm{~mm}-320$ $\mathrm{mm}$. Batas bawah deteksi ketinggian air sebesar $45 \mathrm{~mm}$ ditentukan karena untuk ketinggian air dibawah $45 \mathrm{~mm}$ tidak terjadi perubahan tegangan keluaran detektor. Hal tersebut terjadi karena permukaan membran sudah tidak mengalami pergeseran akibat perubahan tekanan air tidak signifikan, sehingga daya optis berkas balik tidak mengalami perubahan. Untuk batas atas ketinggian air sangat mungkin lebih besar dari hasil yang dicapai pada eksperimen ini. Karena tinggi tangki yang digunakan hanya sebesar $32 \mathrm{~cm}$ atau $320 \mathrm{~mm}$, maka batas itulah yang diperoleh.

Hubungan linier antara tegangan keluaran detektor terhadap ketinggian air diperlihatkan oleh grafik pada Gambar 4. Rentang daerah linier yang dihasilkan nilainya $130 \mathrm{~mm}-320$ $\mathrm{mm}$. Nilai tersebut menunjukkan daerah kerja sensor yang dihasilkan. Sensisivitas sensor sebesar 10,4 $\mu \mathrm{V} / \mathrm{mm}$ diperoleh dari nilai kemiringan grafik pada Gambar 4. Parameter fiber couplerr sebagai sensor ketinggian air hasil penelitian ini diperlihatkan pada Tabel 1.
Membran dari bahan polyisuprene yang digunakan pada penelitian ini mudah rusak jika berinteraksi dengan pelumas atau bahan bakar. Karena itu pada penelitian zat cair yang digunakan adalah air. Jika digunakan membran dari bahan yang tidak rusak ketika berinteraksi dengan bahan bakar, maka metode yang telah dihasilkan ini sangat menjanjikan sebagai sensor ketinggian untuk bahan bakar atau pelumas karena terjamin keamanannya dari ledakan. Hal tersebut yang menjadi salah satu keunggulan sensor menggunakan metode op-

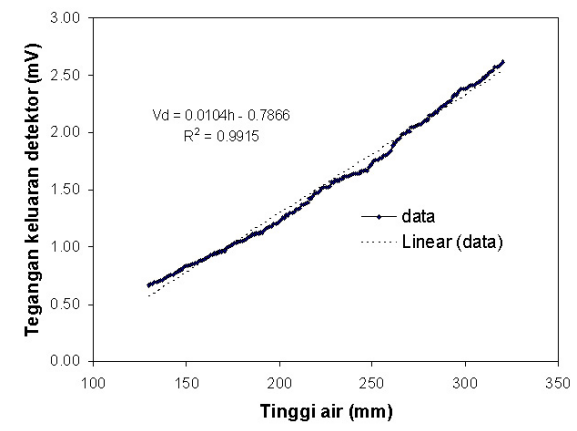

Gambar 4: Grafik linier hubungan antara tegangan keluaran detektor terhadap ketinggian air.

TABEL I: Parameter sensor ketinggian air menggunakan multimode fiber couplerr

\begin{tabular}{lc}
\hline \hline Parameter & Nilai \\
\hline Resolusi $(\mathrm{mm})$ & 1 \\
Jangkauan $(\mathrm{mm})$ & $45-320$ \\
Daerah linier $(\mathrm{mm})$ & $130-320$ \\
Sensitivitas ( V/mm) & 10,4 \\
\hline \hline
\end{tabular}

tik. Elastisitas bahan membran juga dapat digunakan variabel dalam mendesain sensor ketinggian zat cair menggunakan fiber couplerr agar dihasilkan sensor yang dapat bekrja secara optimal khususnya jangkauan ketinggian zat cair.

\section{SIMPULAN}

Dengan menggunakan prinsip hidrostatis, multimode fiber couplerr dapat mendeteksi ketinggian air secara kontinyu dengan rentang deteksi $45 \mathrm{~mm}$ - $320 \mathrm{~mm}$ dan resolusi sebesar $1 \mathrm{~mm}$. Metode yang telah dihasilkan tersebut sangat memungkinkan dikembangkan sebagai sensor ketinggian bahan bakar cair dengan terjamin keamanannya dari ledakan.
[1] Samian, Jurnal Ilmu Dasar, 11 (2), 83 - 186 (2010).

[2] Samian, Gatut Yudoyono, Jurnal Fisika dan Aplikasinya, 6 (100104), 1 - 4 (2010).

[3] Binu, S. V.P. Mahadevan Pillai, N. Chandrasekaran, Optic \& Laser Technology, 39, 1537 - 1543 (2007).

[4] Hocker G.B., Applied Optic, 19, 98 - 107 (1980).
[5] Hossein Golnabi, Optics and Lasers in Engineering, 41, 801-812 (2004).

[6] Pekka Raatikainen, Ivan Kassamakov, Roumen Kakanakov, Mauri Luukkala, Sensors and Actuators, A 58, 93-97 (1997).

[7] M. Lomer, J. Arrue , C. Jauregui, P. Aiestaran, J. Zubia, J.M. Lopez-Higuera, Sensors and Actuators, A 137, 68-73 (2007). 
[8] Kyung-Rak Sohn, Joon-Hwan Shim, Sensors and Actuators, A 152, 248-251(2009).

[9] C. Vzquez, A.B. Gonzalo, S. Vargas, J. Montalvo, Sensors and Actuators, A 116, 22-32 (2004).

[10] S. A. Reza, N. A. Riza, Optics Communications, 283, 3391-
3397 (2010).

[11] Samian, Yono Hadi Pramono, Ali Yunus Rohedi, Febdian Rusydi, AH Zaidan, Journal of Optoelectronics and Biomedical Materials, 1 (3), 303 - 308 (2009). 